\title{
Growth, reproduction and recruitment of Silvetia siliquosa (Fucales, Phaeophyceae) transplants using polyethylene rope and natural rock methods
}

\author{
Xu Gao ${ }^{1}$, Han Gil Choi ${ }^{1, *}$, Seo Kyoung Park ${ }^{1}$, Jung Rok Lee ${ }^{1}$, Jeong Ha Kim² ${ }^{2}$ Zi-Min Hu ${ }^{3}$ \\ and Ki Wan Nam ${ }^{4}$ \\ ${ }^{1}$ Faculty of Biological Science and Institute for Environmental Science, Wonkwang University, Iksan 54538, Korea \\ ${ }^{2}$ Department of Biological Sciences, Sungkyunkwan University, Suwon 16419, Korea \\ ${ }^{3}$ Key Laboratory of Experimental Marine Biology, Institute of Oceanology, Chinese Academy of Sciences, Qingdao 266071, \\ China \\ ${ }^{4}$ Department of Marine Biology, Pukyong National University, Busan 48513, Korea
}

Silvetia siliquosa is an ecologically and commercially important brown alga that is harvested from its natural habitats, but its population has recently been diminishing along the Korean coast. To develop new techniques for algal population restoration, we tested two newly developed transplantation methods (using polyethylene ropes and natural rock pieces) at two study sites, Gwanmaedo and Yeongsando, on the southwest coast of Korea, from May to November 2014. The transplants on polyethylene ropes showed significantly greater survival, maturity, and growth than those on natural rocks at both study sites. Newly recruited juveniles $(<3 \mathrm{~cm})$ of S. siliquosa increased remarkably from May to December near the transplants on polyethylene ropes and natural rocks. Therefore, we suggest that transplantation using polyethylene ropes is more effective than using natural rocks to restore the population of S. siliquosa in Korea.

Key Words: growth; maturity; recruitment; Silvetia siliquosa; survival; transplantation

\section{INTRODUCTION}

Seaweed beds play an important role in maintaining the biodiversity of understory flora and fauna through reduction of physical stresses (desiccation, temperature fluctuation, and wave action) and supporting herbivores, detritivores, filter feeders, and their associated food webs (Bertness et al. 1999, Christie et al. 2003, Rodríguez 2003, Lorentsen et al. 2010, Choi et al. 2015, Kim et al. 2015, Ogandaga et al. 2016, Scrosati 2017). In recent years, there have been reports of a worldwide reduction in seaweed beds, which is possibly due to various hu- man activities (i.e., sedimentation, oil spills, and heavy metal pollution) and climate change (Müller et al. 2009, Wernberg et al. 2011, Díez et al. 2012, Kang and Kim 2016, Scrosati 2016). Because of the importance of seaweed resources for conservation of the coastal environment, the development of effective methods for restoration has started to receive extensive attention.

Re-establishment of declining natural seaweed populations is a common strategy to increase their abundance, and recover the ecosystem functions of degraded or dis-
(9) $\$$ This is an Open Access article distributed under the terms of the Creative Commons Attribution Non-Commercial License (http://creativecommons.org/licenses/by-nc/3.0/) which permits unrestricted non-commercial use, distribution, and reproduction in any medium, provided the original work is properly cited.
Received September 1, 2017, Accepted December 6, 2017

* Corresponding Author

E-mail: hgchoi@wku.ac.kr

Tel: +82-63-850-6579, Fax: +82-63-857-8837 
turbed natural habitats (Hernández-Carmona et al. 2000). Numerous transplantation methods were applied in the northern hemisphere by using large brown algae, such as Fucus, Macrocystis, Nereocystis, and Cystoseira (Stekoll and Deysher 1996, Hernández-Carmona et al. 2000, Carney et al. 2005, Susini et al. 2007), to recover barren areas where seaweed had disappeared because of various biotic or abiotic causes (Jeon et al. 2015). Asian countries including Korea and Japan have also attempted to recover lost marine forests from barren grounds (Largo and Ohno 1993, Terawaki et al. 2001, Watanuki et al. 2010). Applied reconstruction methods for marine forests primarily included providing spore bags as a seed bank and transplanting juveniles or adults to artificial reefs in the subtidal zone (Largo and Ohno 1993, Serisawa et al. 2002, Kim et al. 2013). However, these methods are expensive, laborious, and difficult because of the necessity of SCUBA diving. Therefore, an easy, low-cost, and effective restoration method needs to be explored.

The brown alga Silvetia siliquosa (Tseng et Chang) Serrão, Cho, Boo \& Brawly is one of the most ecologically and economically important algal species and grows in the mid and low intertidal zones of moderate wave-exposed shores in Korea (Hwang et al. 2015, Han et al. 2016). In general, S. siliquosa grows from March to June (or July), produces receptacles in summer (June-August), and dies back in September after reproduction period (Hwang et al. 2015). New recruits ( $<3 \mathrm{~cm}$ long) can be found on the rocky shore from November to February (Hwang et al. 2015). Previously, S. siliquosa was widely distributed along the western and southern coasts of Korea. However, because of its continuous decline from the mid-1990s onward (Song et al. 1996, Lee et al. 1997), at present, the species is only found along the rocky shores of the offshore islands of southern Korea. The causes of the sudden decrease in S. siliquosa populations are not clear, but one possible cause is over-harvesting because of its higher market price (approximately 10 dollars $\mathrm{kg}^{-1}$ wet weight) than that of other edible seaweeds such as Porphyra spp. and Undaria pinnatifida. Because of the high economic value of $S$. siliquosa, the development of an effective restoration method that can increase its abundance and distribution range is strongly desired.

Thus, the aim of this study was to develop and choose a suitable restoration method, which increases or maintains $S$. siliquosa population under severe overharvesting stress. We tested two transplantation methods by comparing the growth, survival, and maturation of S. siliquosa at two study sites to find out a proper restoration method. Furthermore, we also examined the transplant effects on the recruitment of S. siliquosa at Yeongsando site with very low biomass. The results of this study could provide important information for seaweed population restoration in Korea and possibly in other parts of the world.

\section{MATERIALS AND METHODS}

\section{Study site}

Field studies were conducted at Gwanmaedo $\left(34^{\circ} 23^{\prime}\right.$ $\left.\mathrm{N}, 126^{\circ} 03^{\prime} \mathrm{E}\right)$ and Yeongsando ( $\left.34^{\circ} 65^{\prime} \mathrm{N}, 125^{\circ} 46^{\prime} \mathrm{E}\right)$, both located in a National Park, Jeonnam, Korea (Fig. 1). The distance between the two study sites is approximately $75 \mathrm{~km}$. In the field survey undertaken in February 2014, S. siliquosa occurred abundantly in the mid intertidal zone of the semi-exposed Gwanmaedo shore with a biomass of $510.13 \mathrm{~g}$ wet wt $\mathrm{m}^{-2}(\mathrm{n}=3$ replicates), but was less abundant at Yeongsando with very low biomass of 0.01 $\mathrm{g}$ wet wt. $\mathrm{m}^{-2}(\mathrm{n}=3$ replicates). Seawater temperatures from May to November 2014 ranged from 15.7 to $22.5^{\circ} \mathrm{C}$ at Gwanmaedo and from 13.4 to $20.2^{\circ} \mathrm{C}$ at Yeongsando (Table 1). The range of year-round tidal depth was 0.3-3.7 $\mathrm{m}$ at Gwanmaedo and 0.4-3.6 $\mathrm{m}$ at Yeongsando (Korean Hydrographic and Oceanographic Administration).

\section{Transplantation}

Transplantation of S. siliquosa thalli was conducted using polyethylene rope and natural tuffaceous sandstone. Thalli were transplanted at the two study sites at a shore height between +1.04 and $+0.27 \mathrm{~m}$ above mean lower low water, which is consistent with their habitat range at collection site.

Thalli of S. siliquosa were collected from natural populations at Gwanmaedo on May 10, 2014 and transported indoors immediately using ice boxes filled with seawater. Healthy thalli of lengths between 4 and $9 \mathrm{~cm}$ were selected, inserted in some strings (1.2-1.5 $\mathrm{m}$ in length and 3 $\mathrm{mm}$ in diameter) at $5 \mathrm{~cm}$ intervals, and fixed with instantaneous adhesive glue. The following day, the strings with thalli were fixed on the polyethylene ropes (14 $\mathrm{mm}$ in diameter) with plastic cable ties (Fig. 2A). Next, these ropes

Table 1. Average seawater temperatures $\left({ }^{\circ} \mathrm{C}\right)$ at the two study sites of Gwanmaedo and Yeongsando from May to November 2014

\begin{tabular}{cccccccc}
\hline Site & May & Jun & Jul & Aug & Sep & Oct & Nov \\
\hline Gwanmaedo & 15.8 & 19.0 & 21.3 & 22.5 & 21.8 & 20.3 & 15.7 \\
Yeongsando & 13.4 & 16.3 & 19.1 & 20.2 & 19.7 & 18.6 & 15.2 \\
\hline
\end{tabular}



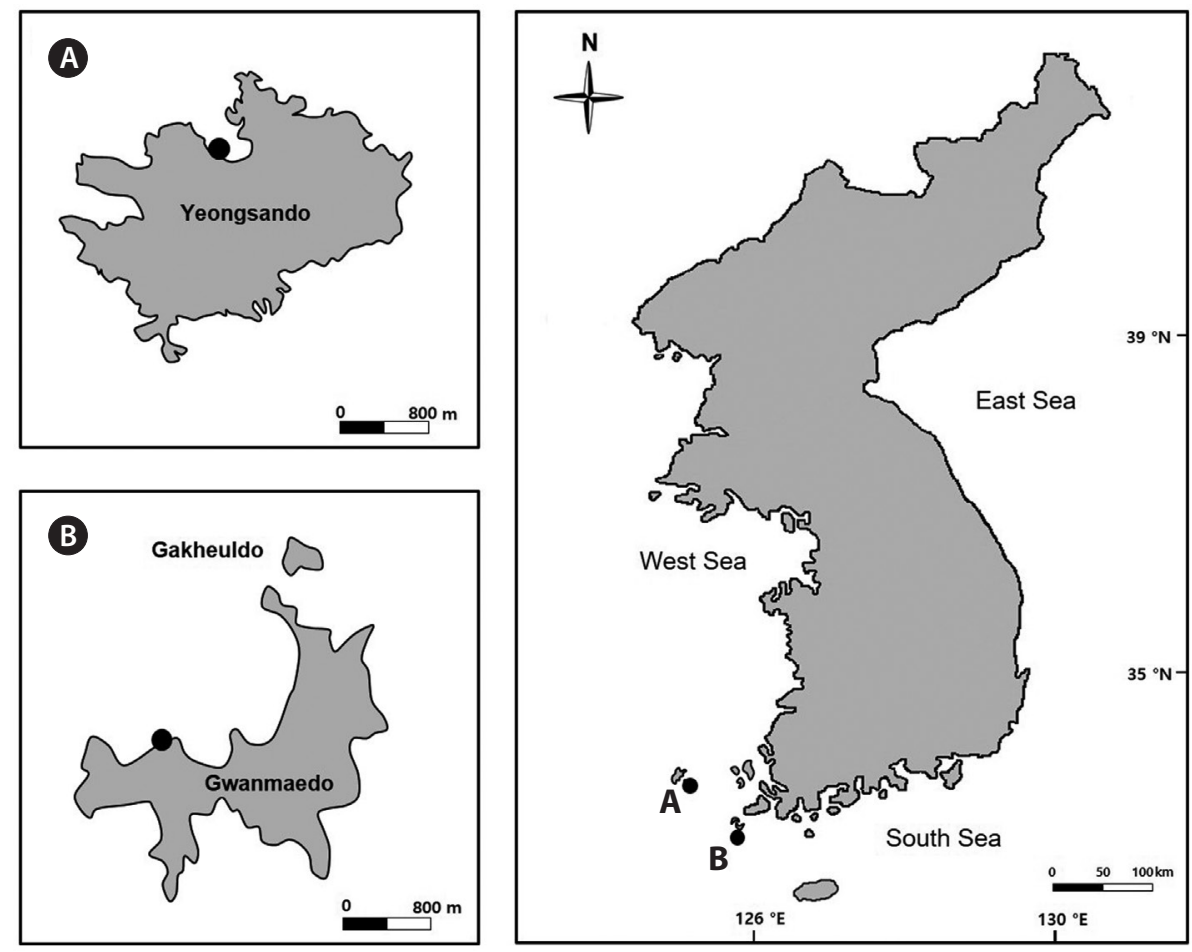

Fig. 1. Map of the two study sites, Yeongsando, Sinan (A) and Gwanmaedo, Jindo (B) located on the southwestern coast of Korea.

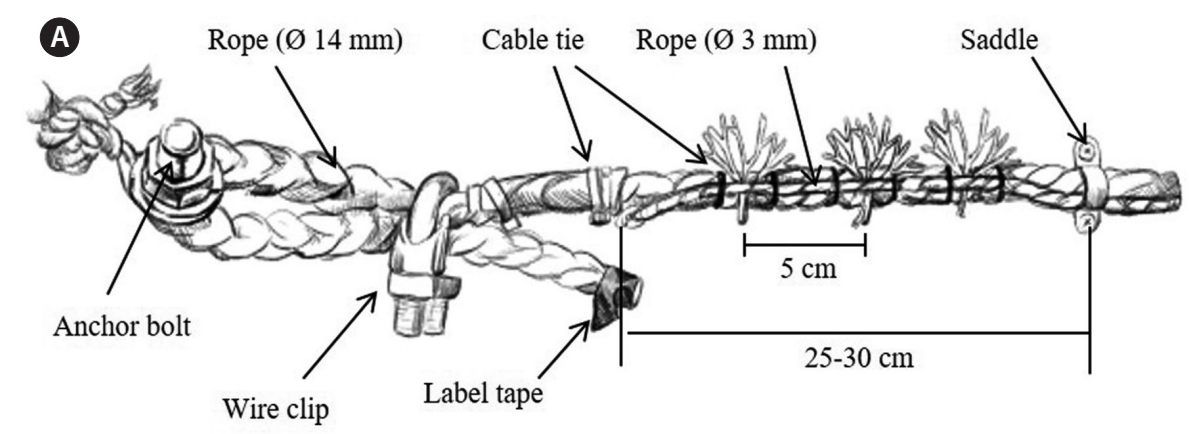

B

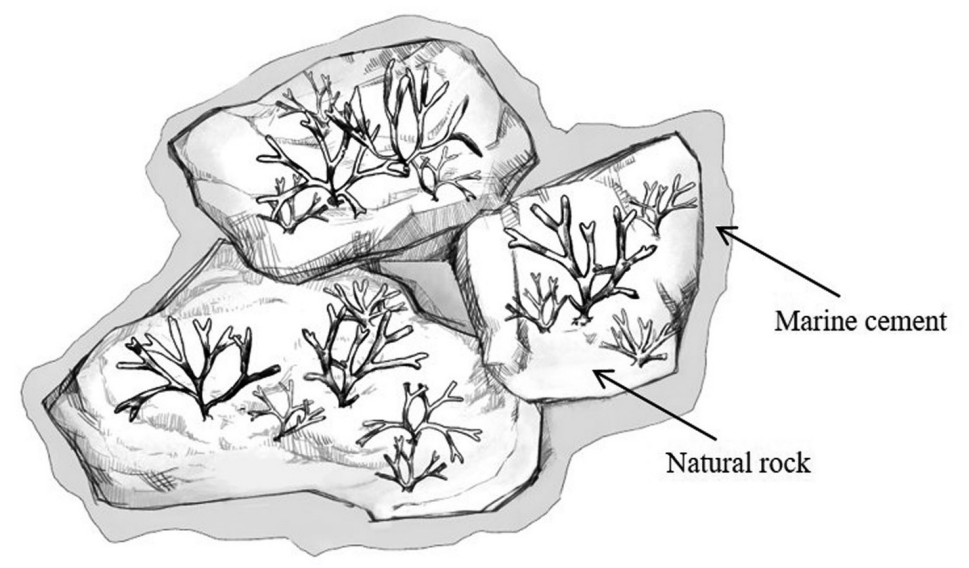

Fig. 2. Transplantation methods. Rope method (A) and stone method (B). 

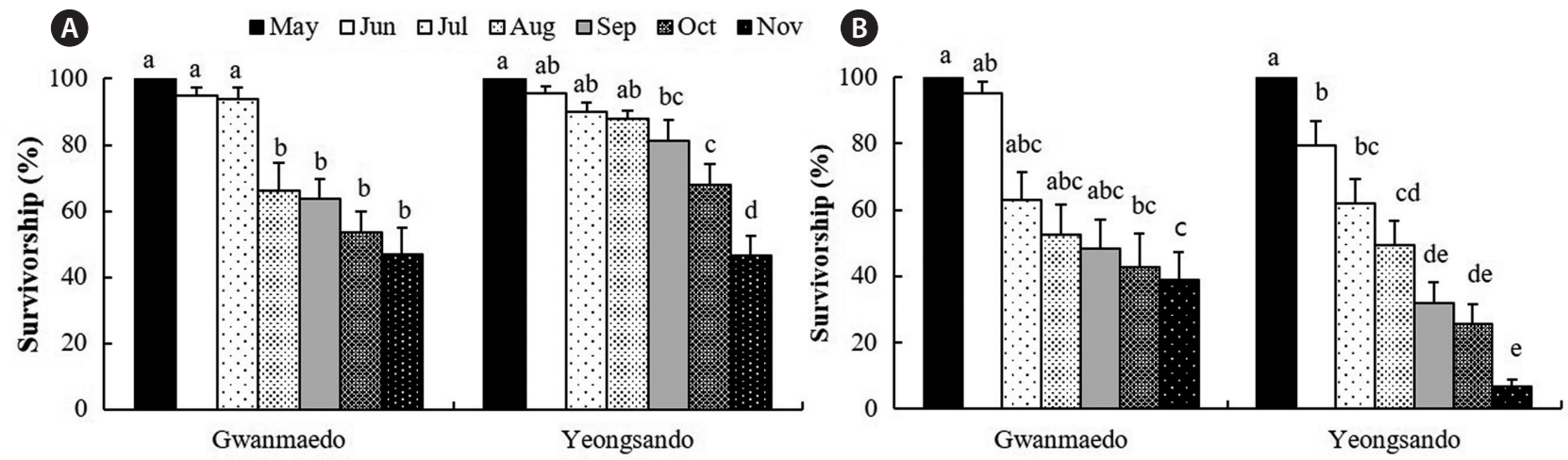

Fig. 3. The survivorship (\%) of Silvetia siliquosa transplants using rope (A) and stone (B) methods over the study period at Gwanmaedo and Yeongsando. Data represent mean \pm standard error. Different letters indicate significant differences between the groups determined by Tukey's honest significant difference test.

were fixed into the rocks with anchor pines at $25-30 \mathrm{~cm}$ intervals (Fig. 2A). Transplantation using polyethylene ropes was carried out on the rocky shores of Gwanmaedo on May 12 and at Yeongsando on May 13. Six replicate ropes with a total of 90-95 transplants were established at each study site (Table 2).

Natural rock pieces (hereafter called natural stone) with $S$. siliquosa thalli were obtained by cutting the intertidal rocks at Gwanmaedo on May 11, 2014. The cut stones with healthy $4-6 \mathrm{~cm}$ long thalli were selected and carefully placed in ice boxes with seawater. Each stone had more than 9 transplants and surface area between 160 and $200 \mathrm{~cm}^{2}$. The stones were fixed to the natural rocks of Gwanmaedo and Yeongsando using underwater epoxy cement (mixed cement powder and seawater at a ratio of $3: 1$ ) after removing all organisms inhabiting the rock surfaces by using a steel brush. Four replicate stones were established at each study site with a total of 69-72 transplants (Table 2).

\section{Measurements}

After transplantation in May, the survival of S. siliquosa transplants was monitored for 6 months from June to

Table 2. Experimental data on Silvetia siliquosa transplants using rope and stone methods at the two study sites of Gwanmaedo and Yeongsando

\begin{tabular}{clccc}
\hline Method & Studysite & Replicates & $\begin{array}{c}\text { Transplants } \\
\text { per replicate }\end{array}$ & $\begin{array}{c}\text { Total } \\
\text { transplants }\end{array}$ \\
\hline Rope & Gwanmaedo & 6 & $10-20$ & 95 \\
& Yeongsando & 6 & 15 & 90 \\
Stone & Gwanmaedo & 4 & $9-27$ & 72 \\
& Yeongsando & 4 & $10-26$ & 69 \\
\hline
\end{tabular}

November 2014. Survival percentage was calculated as the number of transplants remaining at each stage divided by the total number of transplants at the beginning of the experiment. Maturity percentage was calculated as the number of transplants with receptacles at each stage divided by the total number of transplants. To examine the vegetative growth and reproductive efforts of transplants, the maximal plant length (from holdfast to apices) and width (from left to right of spread thallus) were measured, and the number of receptacles was counted for each individual plant at each stage.

New recruits originating from fertile $S$. siliquosa transplants were estimated using the density of juvenile thalli ( $<3 \mathrm{~cm}$ long) observed on the rocky shore and transplantation rope of Yeongsando. Ten quadrats $(25 \times 25 \mathrm{~cm})$ were randomly placed on the natural rocks near the six ropes containing transplants, and S. siliquosa juveniles were counted in May and December. In addition, the number of newly recruited juveniles of S. siliquosa on the ropes was examined at the final stage, in December 2014.

\section{Statistical analysis}

A two-way analysis of variance (ANOVA) was applied to test the effects of sampling month and study site on the survival, maturity, and growth (length and width) of S. siliquosa for rope and stone transplant methods. Prior to analysis, homogeneity of variance was tested using Cochran's test. Where appropriate, data were transformed before analysis to meet the assumptions of parametric tests (Sokal and Rohlf 1995). Statistical analyses were conducted using STATISTICA version 5.0 software (Statsoft Inc., Tulsa, OK, USA). 

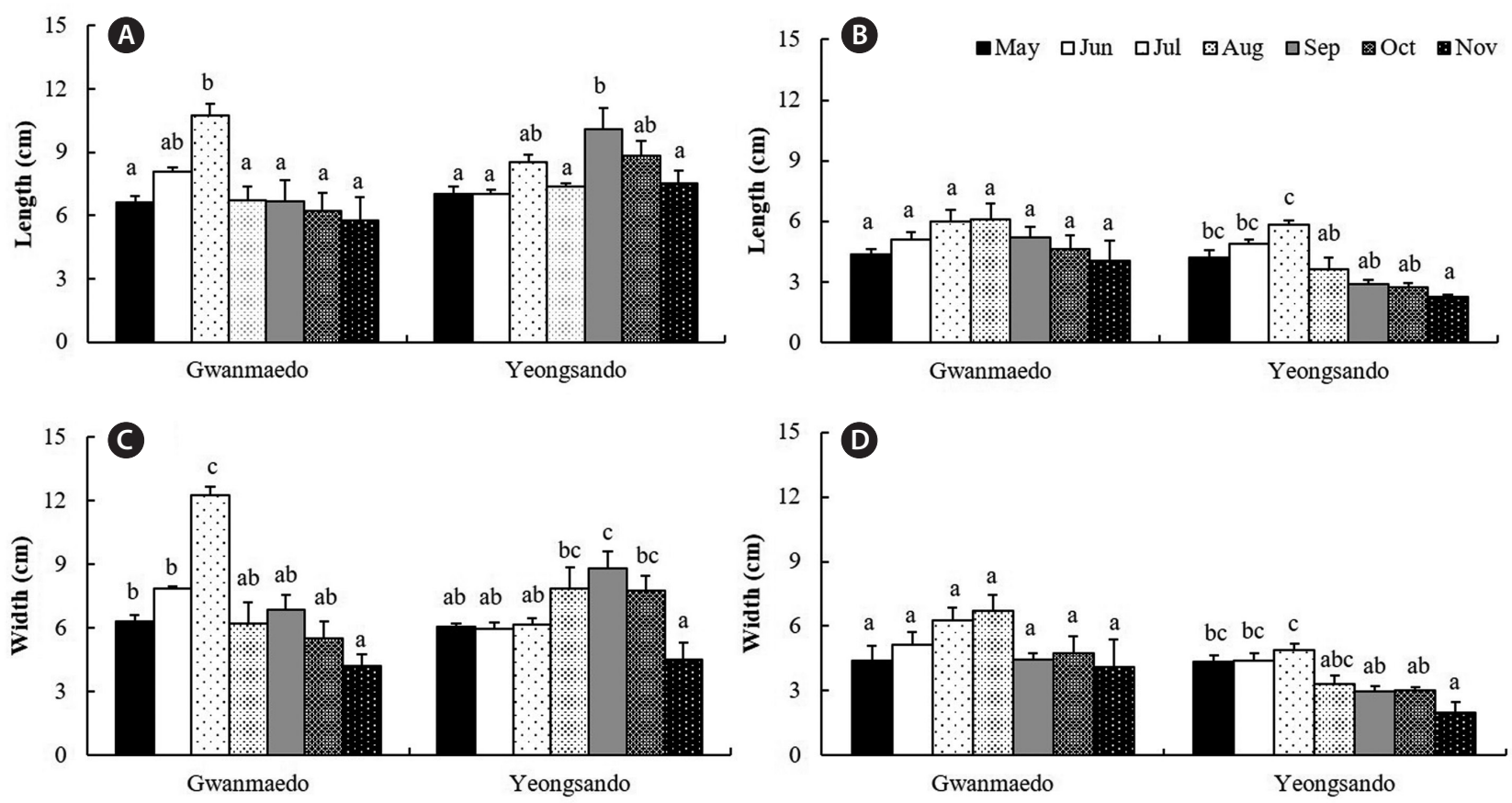

Fig. 4. The length and width of Silvetia siliquosa transplants using rope (A \& C) and stone (B \& D) methods over the study period at Gwanmaedo and Yeongsando. Data represent mean \pm standard error. Different letters indicate significant differences between the groups determined by Tukey's honest significant difference test.

\section{RESULTS}

\section{Survivorship}

Silvetia siliquosa transplants survived at rates of over 90 and $40 \%$ after two and six months (in November), respectively, except for the stone transplants ( $7 \%$ survivorship) at Yeongsando (Fig. 3). The survivorship of the transplants was significantly different between the study sites and between the sampling months (Table 3). Also, the survivorship of S. siliquosa transplants depended on the transplantation method at each study site; rope transplants showed significantly higher survivorship at Yeongsando, but stone transplants survived better at Gwanmaedo than at Yeongsando (Fig. 3). The survivorship was higher $(9-40 \%)$ for rope transplants compared to stone transplants in November 2014 (Fig. 3).

\section{Growth}

Rope transplants of $S$. siliquosa were $7 \mathrm{~cm}$ long at the initial stage in May and grew up to $11 \mathrm{~cm}$ in July at Gwanmaedo and reached to $10 \mathrm{~cm}$ in September at Yeongsando (Fig. 4A). Monthly average lengths of rope transplants were significantly larger in July and September at Gwanmaedo and Yeongsando, respectively, but no significant differences in plant length of stone transplants were found between these months at Gwanmaedo (Table 4, Fig. 4A \& B). After maximal growth, frond lengths of transplanted algae gradually became shorter until the end of experiment at

Table 3. Analysis of variance (two-way ANOVA) for the effects of study site and collection month on survivorship of Silvetia siliquosa transplants using by rope and stone transplantation

\begin{tabular}{|c|c|c|c|c|c|c|}
\hline \multirow{2}{*}{ Factor } & \multicolumn{3}{|c|}{ Rope } & \multicolumn{3}{|c|}{ Stone } \\
\hline & df & F & p-value & df & F & p-value \\
\hline Site (S) & 1 & 6.65 & $<0.05$ & 1 & 6.07 & $<0.05$ \\
\hline Month (M) & 6 & 29.05 & $<0.001$ & 6 & 18.57 & $<0.001$ \\
\hline Interaction $(\mathrm{S} \times \mathrm{M})$ & 6 & 2.03 & 0.073 & 6 & 0.78 & 0.589 \\
\hline
\end{tabular}


the two sites and using the two transplantation methods (Fig. 4A \& B). Average frond lengths of transplants were significantly larger at Yeongsando than at Gwanmaedo, and monthly differences were also observed (Table 4, Fig. 4). However, the stone transplants grew longer at Gwanmaedo than at Yeongsando.

Similarly, S. siliquosa transplanted by rope method grew faster in frond width until July and then died back at Gwanmaedo, whereas the transplants of Yeongsando grew slowly and reached the maximal width in September (Fig. 4C). Plant width of the stone transplants was significantly longer in July than during the other months at Yeongsando (Fig. 4D). However, no growth differences were found in the stone transplants at Gwanmaedo (Fig. 4D). Stone and rope transplants grew significantly better in plant width at Gwanmaedo than at Yeongsando (Table 4, Fig. 4D). Significant interactions were observed between study sites and months on the width of rope transplants (Table 4).

\section{Reproduction}

After transplantation to Gwanmaedo and Yeongsando, the maturity of rope transplants increased by approximately $20-30 \%$ within two months, and it was significantly different between study sites or sampling months (Table 5, Fig. 5). Maturity of rope transplants significantly increased between June and July, and then it rapidly declined at Gwanmaedo, but it was slowly declined at Yeongsando (Fig. 5A). In case of stone transplants, maturity increased from May to June (or July) and then declined rapidly at both study sites (Fig. 5B). Maturity of stone transplants was not significantly different between the study sites but varied between sampling months (Table 5, Fig. 5). Also, the maturity of $S$. siliquosa was greater for rope transplants than for stone transplants (Fig. 5A \& B).

Rope transplants of $S$. siliquosa produced receptacles, and the number of receptacles of individual thalli increased from 4 receptacles in May at the transplantation stage to 17 receptacles after two months (in July at Gwanmaedo) and four months (in September at Yeongsando) as shown in Fig. 5C. The number of receptacles of rope transplants were significantly greater at Yeongsando than at Gwanmaedo and monthly variations were also observed in the number of receptacles per frond (Table 5, Fig. 5). Receptacle production of stone transplants was not significantly different between the two study sites, but monthly differences in receptacle number were observed only at Yeongsando (Table 5, Fig. 5D). These results

Table 4. Analysis of variance (two-way ANOVA) for the effects of study site and collection time on length and width of Silvetia siliquosa transplants using by rope and stone transplantation

\begin{tabular}{|c|c|c|c|c|c|c|}
\hline \multirow{2}{*}{ Factor } & \multicolumn{3}{|c|}{ Length } & \multicolumn{3}{|c|}{ Width } \\
\hline & df & F & p-value & df & F & p-value \\
\hline \multicolumn{7}{|l|}{ Rope } \\
\hline Site (S) & 1 & 6.77 & $<0.05$ & 1 & 3.91 & 0.052 \\
\hline Month (M) & 6 & 7.47 & $<0.001$ & 6 & 14.15 & $<0.001$ \\
\hline Interaction $(\mathrm{S} \times \mathrm{M})$ & 6 & 7.08 & $<0.001$ & 6 & 15.27 & $<0.001$ \\
\hline \multicolumn{7}{|l|}{ Stone } \\
\hline Site (S) & 1 & 57.18 & $<0.001$ & 1 & 62.76 & $<0.001$ \\
\hline Month (M) & 6 & 7.05 & $<0.001$ & 6 & 5.14 & $<0.001$ \\
\hline Interaction $(\mathrm{S} \times \mathrm{M})$ & 6 & 4.62 & $<0.001$ & 6 & 1.25 & 0.301 \\
\hline
\end{tabular}

Table 5. Analysis of variance (two-way ANOVA) for the effects of study site and collection time on the maturity and number of receptacle per plant of Silvetia siliquosa transplants using by rope and stone transplantation

\begin{tabular}{|c|c|c|c|c|c|c|}
\hline \multirow{2}{*}{ Factor } & \multicolumn{3}{|c|}{ Maturity } & \multicolumn{3}{|c|}{ No. of receptacles } \\
\hline & df & $\mathbf{F}$ & p-value & df & $\mathrm{F}$ & p-value \\
\hline \multicolumn{7}{|l|}{ Rope } \\
\hline Site (S) & 1 & 23.45 & $<0.001$ & 1 & 4.52 & $<0.05$ \\
\hline Month (M) & 6 & 15.30 & $<0.001$ & 6 & 5.73 & $<0.001$ \\
\hline Interaction $(\mathrm{S} \times \mathrm{M})$ & 6 & 4.75 & $<0.001$ & 6 & 10.88 & $<0.001$ \\
\hline \multicolumn{7}{|l|}{ Stone } \\
\hline Site (S) & 1 & 2.46 & 0.12 & 1 & 2.37 & 0.13 \\
\hline Month (M) & 6 & 6.88 & $<0.001$ & 6 & 6.42 & $<0.001$ \\
\hline Interaction $(\mathrm{S} \times \mathrm{M})$ & 6 & 1.91 & 0.10 & 6 & 1.92 & 0.10 \\
\hline
\end{tabular}



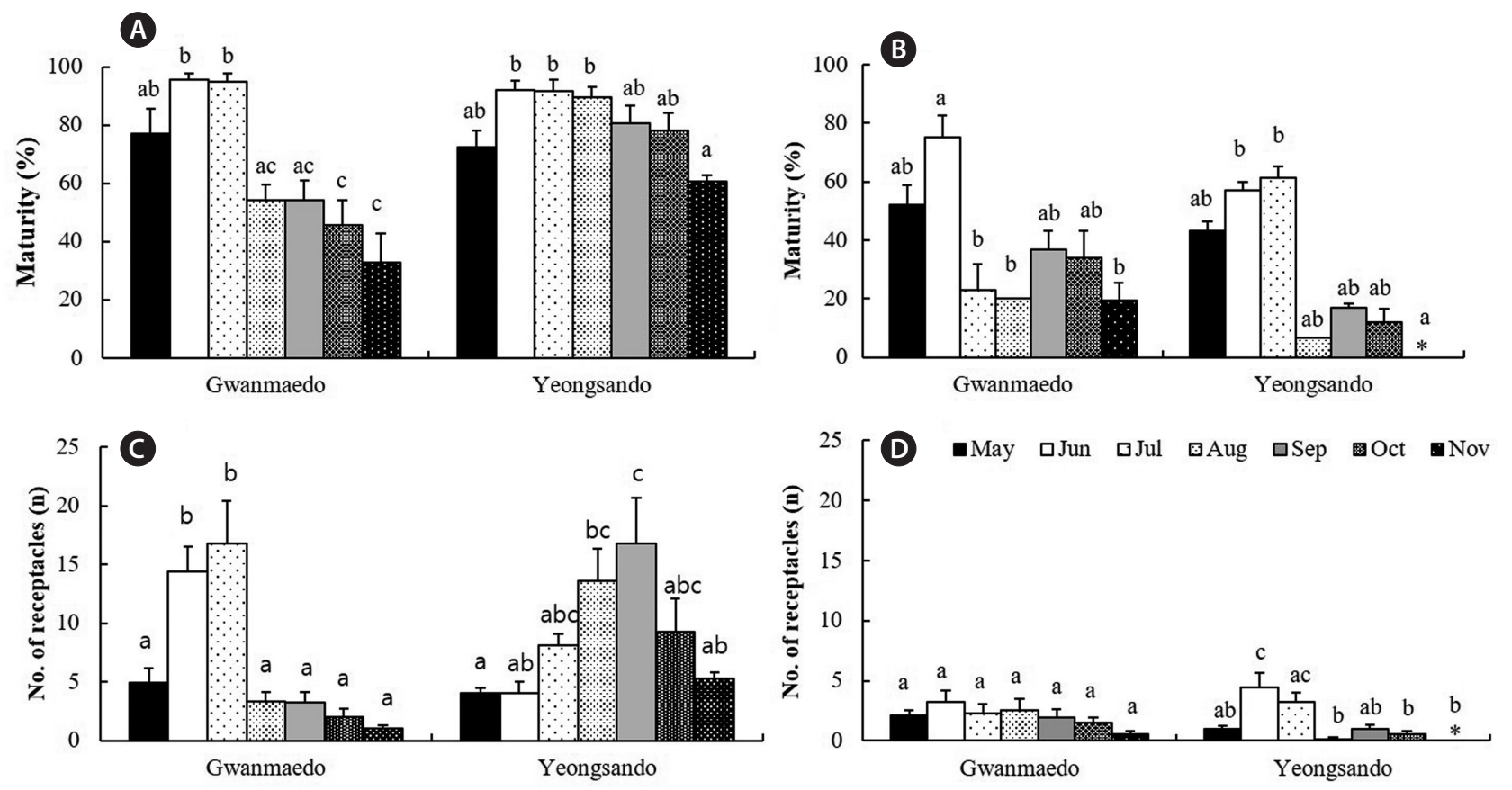

Fig. 5. Maturity (\%) and number of receptacles of Silvetia siliquosa transplants using rope (A \& C) and stone (B \& D) methods over the study period at Gwanmaedo and Yeongsando. Data represent mean \pm standard error. Different letters indicate significant differences between the groups determined by Tukey's honest significant difference test. Asterisks $(*)$ indicate no presence.
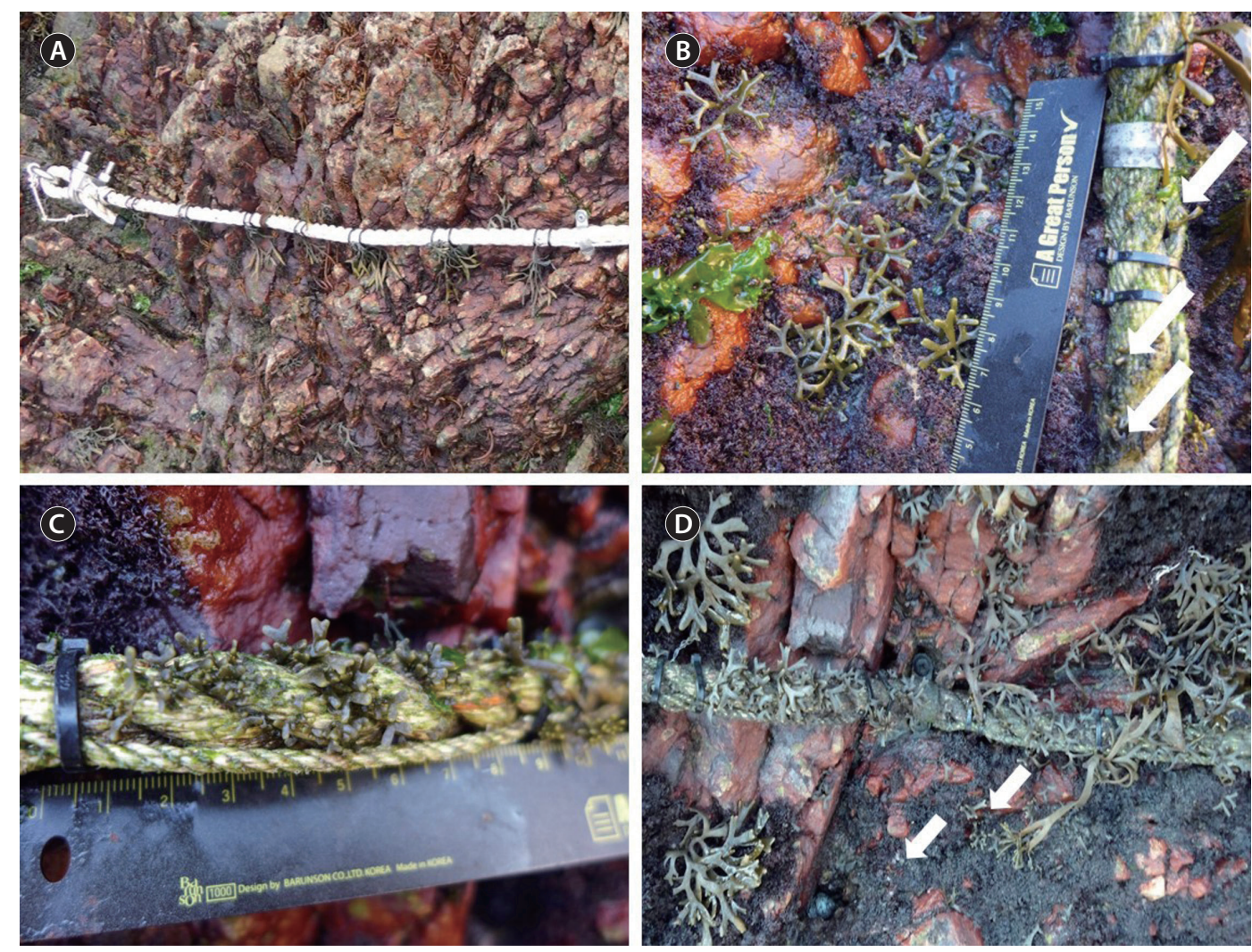

Fig. 6. Adult transplants and new recruits of Silvetia siliquosa. Rope transplantation in May (A), recruits growing on the natural rock and on the established rope (arrows) in October (B), new recruits on the rope in November (C), and new recruits grown on the rope and natural rock surface (arrows) in December (D). 
showed that reproduction of S. siliquosa occurred mainly in summer, but the reproductive peak period was slightly earlier at Gwanmaedo than at Yeongsando. Furthermore, receptacle production was significantly greater in rope transplants than in stone transplants (Fig. 5C \& D).

\section{Recruitment}

On the rocky shore of Yeongsando, the density of S. siliquosa significantly increased over the study period and new recruits $(<3 \mathrm{~cm})$ were easily observed from October 2014 (Fig. 6). At the Yeongsando rocky shore, the initial juvenile density of S. siliquosa was $89.60 \pm 12.44$ plants $\mathrm{m}^{-2}$ (mean \pm standard error [SE], $\mathrm{n}=10$ ) in May, at the transplantation stage. Seven months after transplantation, juvenile density remarkably increased up to $372.80 \pm$ 34.57 plants $\mathrm{m}^{-2}($ mean $\pm \mathrm{SE}, \mathrm{n}=10)$ in December $\left(\mathrm{F}_{1,18}=\right.$ 59.42, $\mathrm{p}<0.001$ ). In addition, approximately 1,000 new recruits (4-10 recruits $1 \mathrm{~cm} \mathrm{rope}^{-1}$ ) were observed around these transplantation ropes with transplants (Fig. 6).

\section{DISCUSSION}

The transplants of S. siliquosa on polyethylene ropes showed better survival, growth, and more successful reproduction on the rocky shores of Gwanmaedo and Yeongsando than those on the natural stones in the present study. These results indicate that S. siliquosa showed no obvious negative effects (such as high mortality and size reduction) because the transplants grew and matured well at the new environmental conditions. Thus, population restoration of this species is likely to be achieved by transplantation. Better survival, growth, and maturity of the rope transplants compared to stone transplants might be due to the combined effect of multiple factors, such as microscale water movement, desiccation, substratum structure and feeding pressure, which are changed by the transplantation method. For instance, the S. siliquosa transplants grown on the top of polyethylene ropes were exposed at high nutrient availability and low grazing pressure because of fast water movement and less stability at the top of ropes as compared to the center of firmly cemented natural stones with slow laminar flow as described in previous researches (Foster 1975, Aquilino et al. 2009). In addition, the twisted polyethylene ropes with many fine strings provided many crevices containing seawater resulted in reducing desiccation and enhancing growth under desiccation stress of the intertidal zone. Such complex substratum structures of poly- ethylene ropes made increased juvenile recruitment as compared to simple and flat stone surface. However, to elucidate these complex mechanisms, well-designed further researches should be conducted.

Irrespective of the transplantation method, rapid growth of S. siliquosa transplants occurred in summer when seawater temperature was between 13 and $21^{\circ} \mathrm{C}$ at the two study sites. Recently, a summer growth period for S. siliquosa was also recorded by frond length and biomass in the Jindo natural population (Hwang et al. 2015). After transplantation, the S. siliquosa transplants at Gwanmaedo showed significantly greater growth in length and width than those of Yeongsando at the initial stage between May and July. Over the study period, however, the frond lengths of the rope transplants were significantly greater at Yeongsando than at Gwanmaedo, but frond length of stone transplants was higher at Gwanmaedo than at Yeongsando. These results may indicate that the transplants at different study sites had different growth strategies. Compared to the transplants at Yeongsando, the transplants at Gwanmaedo showed relatively faster growth within a shorter period. The difference in growth may be related to the difference in seawater temperature between the two study sites. From May to September 2014, the seawater temperature of Gwanmaedo was $2-3^{\circ} \mathrm{C}$ higher than that of Yeongsando (Table 1). The present results are supported by previous findings that Saccharina japonica grown in high-temperature years showed significantly faster growth compared with $S$. japonica grown in low-temperature years (Gao et al. 2015).

The transplants of S. siliquosa showed a peak in maturity at the initial stage (June and July) in summer for both transplantation methods. Thereafter, the maturity of the rope transplants at Gwanmaedo exhibited a relatively faster decline than at Yeongsando. Furthermore, the receptacles of rope transplants at Gwanmaedo reached their maximum number between May and July, but at Yeongsando, the maximum number occurred two months later in September. These differences implied that reproduction periods of transplants may be slightly different between the two study sites. Previous studies reported that change in temperature as an external ecophysiological trigger is well known in coordinating the reproduction of seaweeds (Lüning et al. 2008). An early shift in sexual reproduction at elevated seawater temperatures has been observed in several species, including Laminaria saccharina (Pang and Lüning 2004), Hizikia fusiformis (Pang et al. 2005), and Sargassum fulvellum (Hwang et al. 2006). Therefore, the difference in seawater temperature between the two study sites was thought to be one of the 
most important environmental factors. In addition, in this study, the lengths of the transplants were slightly different (4-9 $\mathrm{cm}$ long for rope and 4-6 $\mathrm{cm}$ for stone), and this may have also partially affected the reproduction strategy of the transplants. Zou et al. (2006) also reported that the percentage of mature plants in H. fusiformis was higher in larger plants than in smaller plants. In addition, for the successful transplantation of Ecklonia cava, the importance of appropriate plant length of the transplants was emphasized by Kim et al. (2013).

Newly recruited juveniles ( $<3 \mathrm{~cm}$ long) of S. siliquosa were observed on the natural rock bed around the rope transplants after the summer reproduction period. In a pond culture, Huang et al. (2008) reported that Pelvetia siliquosa (i.e., S. siliquosa) grew to $3.75 \mathrm{~cm}$ in frond length with 3-4 branches, after approximately 18 months, from zygotes. In the present study, however, recruited juveniles of S. siliquosa on the established ropes had 2-3 branches after only six months, indicating that juveniles grew faster in the natural environment than in the pond culture condition. Moreover, the density of the recruits on established ropes increased more than four times compared with the initial density at the beginning of the transplantation. These findings suggest that the transplants had a great capacity to survive and grow in the environmental conditions of the two study sites, and also achieved successful reproduction and recruitment. Therefore, our results are encouraging for the potential restoration and re-vegetation of this endangered species in the temperate rocky shores of Korea. However, there are still some other environmental factors, such as competition and grazing, which may prevent the increase of S. siliquosa populations. The feasibility of the restoration needs a variety of ecological studies regarding the transplantation processes and interactions between different environmental factors, which may influence the survival and recruitment of S. siliquosa.

In conclusion, this study demonstrated that polyethylene rope transplantation method showing better survival, growth, and maturity seems to be more appropriate with greater potential for restoration of S. siliquosa populations in Korea as compared to stone transplantation method. Furthermore, many new recruits were observed around the transplants, indicating successful reproduction by transplantation. This study may contribute to the development of an effective way for the re-establishment of some endangered seaweeds, especially those species with economic and ecological importance. In addition, compared to the establishment of artificial seaweed reefs, which is associated with high cost and difficulty, the transplantation methods in this study are cheaper and easier, leading to successful restoration. Further studies should be performed to test the effect of grazing on survival and growth of $S$. siliquosa recruits.

\section{ACKNOWLEDGEMENTS}

We would like to thank anonymous reviewers for helpful comments that improved the manuscript. This paper was supported by Wonkwang University in 2015.

\section{REFERENCES}

Aquilino, K. M., Bracken, M. E. S. \& Faubel, M. N. 2009. Localscale nutrient regeneration facilitates seaweed growth on wave-exposed rocky shores in an upwelling system. Limnol. Oceanogr. 54:309-317.

Bertness, M. D., Leonard, G. H., Levine, J. M., Schmidt, P. R. \& Ingraham, A. O. 1999. Testing the relative contribution of positive and negative interactions in rocky intertidal communities. Ecology 80:2711-2726.

Carney, L. T., Waaland, J. R., Klinger, T. \& Ewing, K. 2005. Restoration of the bull kelp Nereocystis luetkeana in nearshore rocky habitats. Mar. Ecol. Prog. Ser. 302:49-61.

Choi, H. G., Kim, B. Y., Park, S. K., Heo, J. S., Kim, C., Kim, Y. S. \& Nam, K. W. 2015. Effects of wave action and grazers on frond perforation of the green alga, Ulva australis. Algae 30:59-66.

Christie, H., Jørgensen, N. M., Norderhaug, K. M. \& WaageNielsen, E. 2003. Species distribution and habitat exploitation of fauna associated with kelp (Laminaria hyperborea) along the Norwegian coast. J. Mar. Biol. Assoc. U. K. 83:687-699.

Díez, I., Muguerza, N., Santolaria, A., Ganzedo, U. \& Gorostiaga, J. M. 2012. Seaweed assemblage changes in the eastern Cantabrian Sea and their potential relationship to climate change. Estuar. Coast. Shelf Sci. 99:108-120.

Foster, M. S. 1975. Regulation of algal community development in a Macrocystis pyrifera forest. Mar. Biol. 32:331342.

Gao, X., Endo, H. \& Agatsuma, Y. 2015. Effect of increased seawater temperature on biomass, growth, and maturation of Saccharina japonica near its southern limit in northern Japan. J. Appl. Phycol. 27:1263-1270.

Han, S. J., Jeon, D. V., Lee, J. R., Na, Y. J., Park, S. K. \& Choi, H. G. 2016. Marine algal flora and community structure at Gwanmaedo and Yeongsando, Korea. Korean J. Fish. Aquat. Sci. 49:53-60. 
Hernández-Carmona, G., Garcia, O., Robledo, D. \& Foster, M. 2000. Restoration techniques for Macrocystis pyrifera (Phaeophyceae) populations at the southern limit of their distribution in Mexico. Bot. Mar. 43:273-284.

Huang, L. -J., Cai, H. -B., Zhang, H. -J. \& Xu, X. -Y. 2008. Development and utilization of a seaweed natural resource studies on seedling-rearing of Pelvetia siliquosa. Mar. Fish. Res. 29:70-75.

Hwang, E. K., Park, C. S. \& Baek, J. M. 2006. Artificial seed production and cultivation of the edible brown alga, Sargassum fulvellum (Turner) C. Agardh: developing a new species for seaweed cultivation in Korea. J. Appl. Phycol. 18:251-257.

Hwang, E. K., Yoo, H. C., Ha, D. S. \& Park, C. S. 2015. Growth and maturation period of Silvetia siliquosa in the natural population in Jindo, South Korea. Korean J. Fish. Aquat. Sci. 48:745-751.

Jeon, B. H., Yang, K. M. \& Kim, J. H. 2015. Changes in macroalgal assemblage with sea urchin density on the east coast of South Korea. Algae 30:139-146.

Kang, E. J. \& Kim, K.Y.2016. Effects of future climate conditions on photosynthesis and biochemical component of Ulva pertusa (Chlorophyta). Algae 31:49-59.

Kim, J. -H., Kang, E. J., Kim, K., Jeong, H. J., Lee, K., Edwards, M. S., Park, M. G., Lee, B. -G. \& Kim, K. Y. 2015. Evaluation of carbon flux in vegetative bay based on ecosystem production and $\mathrm{CO}_{2}$ exchange driven by coastal autotrophs. Algae 30:121-137.

Kim, Y. D., Shim, J. M., Park, M. S., Hong, J. -P., Yoo, H. I., Min, B. H., Jin, H. -J., Yarish, C. \& Kim, J. K. 2013. Size determination of Ecklonia cava for successful transplantation onto artificial seaweed reef. Algae 28:365-369.

Largo, D. B. \& Ohno, M. 1993. Constructing an artificial seaweed bed. In Ohno, M. \& Critchley, A. T. (Eds.) Seaweed Cultivation and Marine Ranching. Japan International Cooperation Agency, Tokyo, pp. 113-130.

Lee, J. W., Oh, B. -G. \& Lee, H. -B. 1997. Marine algal flora and community of Padori area in the Taean Peninsula, the west coast of Korea. Algae 12:131-138.

Lorentsen, S. -H., Sjøtun, K. \& Grémillet, D. 2010. Multitrophic consequences of kelp harvest. Biol. Conserv. 143:2054-2062.

Lüning, K., Kadel, P. \& Pang, S. 2008. Control of reproduction rhythmicity by environmental and endogenous signals in Ulva pseudocurvata (Chlorophyta). J. Phycol. 44:866873.

Müller, R., Laepple, T., Bartsch, I. \&Wiencke, C. 2009. Impact of oceanic warming on the distribution of seaweeds in polar and cold-temperate waters. Bot. Mar. 52:617-638.

Ogandaga, C. A. M., Choi, H. G., Kim, J. K. \& Nam, K. W. 2016.
Growth responses of Chondrus ocellatus Holmes (Gigartinales, Rhodophyta) to two endophytes, Mikrosyphar zosterae Kuckuck (Ectocarpales, Ochrophyta) and $U l$ vella ramosa (N. L. Gardner) R. Nielsen (Ulvales, Chlorophyta) in culture. Algae 31:363-371.

Pang, S. J., Chen, L. T., Zhuang, D. G., Fei, X. G. \& Sun, J. Z. 2005. Cultivation of the brown alga Hizikia fusiformis (Harvey) Okamura: enhanced seedlings production in tumbled culture. Aquaculture 245:321-329.

Pang, S. J. \& Lüning, K. 2004. Breaking seasonal limitation: year-round sporogenesis in the brown alga Laminaria saccharina by blocking the transport of putative sporulation. Aquaculture 240:531-541.

Rodríguez, S. R. 2003. Consumption of drift kelp by intertidal populations of the sea urchin Tetrapygus niger on the central Chilean coast: possible consequences at different ecological levels. Mar. Ecol. Prog. Ser. 251:141-151.

Scrosati, R. A. 2016. The clonal seaweed Chondrus crispus as a foundation species. Algae 31:41-48.

Scrosati, R. A. 2017. Community-level facilitation by macroalgal foundation species peaks at an intermediate level of environmental stress. Algae 32:41-46.

Serisawa, Y., Yokohama, Y., Aruga, Y. \& Tanaka, J. 2002. Growth of Ecklonia cava (Laminariales, Phaeophyta) sporophytes transplanted to a locality with different temperature conditions. Phycol. Res. 50:201-207.

Sokal, R. R. \& Rohlf, E. J. 1995. Biometry: the principles and practices of statistics in biological research. 3rd ed. W. $\mathrm{H}$. Freeman, New York, 887 pp.

Song, H. S., Seo, K. S. \& Boo, S. M. 1996. Field studies of the brown alga Pelvetia siliquosa with implications for taxonomy and distribution. Algae 11:65-71.

Stekoll, M. S. \& Deysher, L. 1996. Recolonization and restoration of upper intertidal Fucus gardneri (Fucales, Phaeophyta) following the Exxon Valdez oil spill. Hydrobiologia 326/327:311-316.

Susini, M. L., Mangialajo, L., Thibaut, T. \& Meinesz, A. 2007. Development of a transplantation technique of Cystoseira amentacea var. stricta and Cystoseira compressa. Hydrobiologia 580:241-244.

Terawaki, T., Hasegawa, H., Arai, S. \& Ohno, M. 2001. Management-free techniques for restoration of Eisenia and Ecklonia beds along the central Pacific coast of Japan. J. Appl. Phycol. 13:13-17.

Watanuki, A., Aota, T., Otsuka, E., Kawai, T., Iwahashi, Y., Kuwahara, H. \& Fujita, D. 2010. Restoration of kelp beds on an urchin barren: removal of sea urchins by citizen divers in southwestern Hokkaido. Bull. Fish. Res. Agency 32:83-87.

Wernberg, T., Russell, B. D., Moore, P. J., Ling, S. D., Smale, 
D. A., Campbell, A., Coleman, M. A., Steinberg, P. D., Kendrick, G. A. \& Connell, S. D. 2011. Impacts of climate change in a global hotspot for temperate marine biodiversity and ocean warming. J. Exp. Mar. Biol. Ecol. 400:7-16.
Zou, D. H., Gao, K. \& Ruan, Z. 2006. Seasonal pattern of reproduction of Hizikia fusiformis (Sargassaceae, Phaeophyta) from Nanao Island, Shantou, China. J. Appl. Phycol. 18:195-201. 